Int. J. Electrochem. Sci., 12 (2017) $1-9$

\title{
Highly Effective Hydrophilic Modified Carbon Microspheres for Electrochemical Double-layer Capacitors
}

\author{
Lei Yang, Hua Li ${ }^{*}$, Hezhou Liu', Yangyang Zhang ${ }^{1}$ \\ State Key Laboratory of Metal Matrix Composites, Shanghai Jiao Tong University, 800 Dongchuan \\ Road, Shanghai 200240, China \\ *E-mail: lihua11742@163.com
}

doi: $10.20964 / 2017.01 .12$

Received: 23 September 2016 / Accepted: 9 November 2016 / Published: 12 December 2016

In this work, hydrophilic poly(N-vinylpyrrolidone) (PVP) were covalently attached to carbon microspheres (CMS) using the surface-initiate atom transfer radical polymerization method. The synthesis of the materials involves the functionalization of CMS carbon a covalent attachment of PVP. Chemical and morphological changes of the PVP-modified carbon microspheres surface were characterized in detail by X-ray fluorescence spectroscopy and scanning electron microscopy (SEM). Compared with the unmodified CMS, the modified carbon (P-CMS) show higher hydrophilic and have better wettability in an aqueous electrolyte. Owing to the enhanced surface affinity between carbon electrode and electrolyte ions, the P-CMS electrode exhibits much higher capacitance $(230 \mathrm{~F} / \mathrm{g})$ than the CMS electrode $(99 \mathrm{~F} / \mathrm{g}$ ) and better capacitance retention capability. The sample also showed an excellent cycling stability with only about $9 \%$ capacity decay at $0.5 \mathrm{~A} / \mathrm{g}$ after 3000 cycles in $2 \mathrm{M} \mathrm{KOH}$ electrolyte. The easy surface modification method of carbon materials and smart capacitive performance of P-CMS makes it a promising electrode material for supercapacitors.

Keywords: Hydrophilic; supercapacitor; carbon microspheres; atom transfer radical polymerization; poly(N-vinylpyrrolidone)

\section{FULL TEXT}

(C) 2017 The Authors. Published by ESG (www.electrochemsci.org). This article is an open access article distributed under the terms and conditions of the Creative Commons Attribution license (http://creativecommons.org/licenses/by/4.0/). 